\title{
Spironolactone therapy in infants with congestive heart failure secondary to congenital heart disease
}

\author{
SUSAN M HOBBINS, RODNEY S FOWLER, RICHARD D ROWE, AND ANDREW G KOREY \\ Division of Cardiology, Department of Paediatrics, Hospital for Sick Children, Toronto, and \\ Department of Paediatrics, University of Toronto, Canada
}

SUMMARY The efficacy of treatment with spironolactone for congestive heart failure secondary to congenital heart disease was studied in 21 infants under 1 year of age. All received digoxin and chlorothiazide. In addition, group A $(n=10)$ was given supplements of potassium and group B $(n=11)$ received spironolactone. Daily clinical observations of vital signs, weight, hepatomegaly, and vomiting were recorded. Paired $t$ test analysis showed significant reduction in liver size and weight $(P<0.01)$ and respiratory rate $(P<0.05)$ in group $B$, and less significant decreases in group $A$. The incidence of vomiting was slightly lower in group B. We conclude that the addition of spironolactone hastens and enhances the response to standard treatment with digoxin and chlorothiazide in infants with congestive heart failure.

Spironolactone, a pharmacological antagonist of the adrenal mineralocorticoid, ${ }^{1}$ has been used for some years in the treatment of congestive heart failure (CHF). By competitively binding to specific nuclear macromolecules in the distal convoluted renal tubular cells, this agent inhibits aldosterone's regulatory effects on electrolytes, increasing sodium excretion and decreasing potassium excretion. ${ }^{2}$ Spironolactone is particularly effective in the treatment of patients with CHF who are taking diuretics, because it neutralises the kaliuretic effect of the thiazides and enhances natriuresis.

We have used spironolactone in the treatment of CHF for about 10 years at this hospital. However, its use in infants has been poorly documented. We therefore wished to compare the efficacy of spironolactone with that of a conventional potassium supplement, given in conjunction with digoxin and diuretic, in infants who had CHF secondary to congenital heart disease.

\section{Patients and methods}

Any infant aged under 1 year who was admitted to the cardiology ward and who had congenital heart defects with CHF that had been confirmed clinically and radiologically and by history and could not be controlled by the use of digitalis, or had not been treated, was considered for inclusion in the study.

Based on a presentation to the Canadian Paediatric Society in Halifax, Nova Scota, 25-28 June 1978.
We excluded or withdrew from the study any infant in whom any of the following was presento or developed. (1) Renal disease or dysfunction, aso shown by blood urea nitrogen $>8.925 \mathrm{mmol} / \mathrm{l}$ $(25 \mathrm{mg} / 100 \mathrm{ml})$ or hepatic disease or dysfunction. (2) Electrolyte imbalance (serum $\mathrm{Na}^{+}<130 \mathrm{mmol} / \mathrm{I}$ or serum $\mathrm{K}^{+}<3.0$ or $>5.5 \mathrm{mmol} / \mathrm{l}$ ). (3) Cardiac arrhythmia requiring treatment other than digoxin. (4) Blood pressure $>115 \mathrm{mmHg}$ systolic or $>86 \mathrm{~mm}$ $\mathrm{Hg}_{\text {diastolic }}{ }^{3}$ (unless the raised pressure was due to coarctation of the aorta). (5) Acute respiratory infection, such as pneumonia or bronchiolitis. (6) A therapeutic regimen that included acetylsalicylic acid, sodium salicylate, paracetamol, barbiturates, or steroids. (7) Receipt of a spironolactone-blocking agent within 2 weeks of admission, or known sensitivity to spironolactone. (8) Increasing severity of the CHF, necessitating change in treatment. (9) Insufficient data before surgery or development of a chemical abnormality.

Two treatment regimens were devised and a schedule of random allocation to groups $A$ and $B$ was set up. All the infants were to be treated with digoxin and chlorothiazide (Diuril; Frosst, Dorval, Que.). Digitalisation dose of digoxin was $0.05 \mathrm{mg} / \mathrm{kg}$ per day divided into 3 equal doses and then a maintenance dose of $0.005 \mathrm{mg} / \mathrm{kg}$ every 12 hours. Dosage of chlorothiazide was $10-20 \mathrm{mg} / \mathrm{kg}$ per day every 12 hours. In addition, those in group $A$ were to receive potassium supplements $(\mathrm{K}-\mathrm{lyte} / \mathrm{Cl}$; Mead Johnson, Candiac, Que.) at a dose of $1-3 \mathrm{mEq} / \mathrm{kg}$ 
per day and infants in group B were to be given spironolactone, $1-2 \mathrm{mg} / \mathrm{kg}$ per day every 12 hours (Aldactone; made up in $5 \mathrm{mg}$ tablets and given to us by Searle, Oakville, Ont.). Relief of CHF was to be assessed by lower respiratory and pulse rates, smaller hepatic size, and reduction of body weight. ${ }^{4}$

A complete medical history was taken for each patient and a full physical examination was performed before the study. We recorded temperature, pulse and respiratory rates, blood pressure, weight, and degree of hepatomegaly. A 12-lead electrocardiogram and chest roentgenograph were obtained, together with determinations of plasma $\mathrm{Na}^{+}$, chloride $\left(\mathrm{Cl}^{-}\right), \mathrm{pH}, \mathrm{PCO}_{2}$, bicarbonate, plasma urea, and random blood sugar. Infants who required diuresis immediately to relieve severe respiratory distress were given frusemide (Lasix; Hoechst, Montreal, Que.), $1 \mathrm{mg} / \mathrm{kg}$, intravenously or intramuscularly.

\section{Study protocol}

On entering the study, each infant was randomly allocated to one of the treatment regimens and was assigned an identification number. None entered the study more than once.

The infants were fed a routine ward diet of SMA 20 , Enfalac milk, or $2 \%$ milk, plus solids, juices, and commercial rice pablum* or baby foods, according to age. Types and volumes of intake were recorded on a diet-sheet and were summarised every 24 hours.

Clinical measurements were made daily at 0800 hours before being fed. The infants were weighed naked, each time on the same scales. Records of vital signs-blood pressure, respiratory rate, pulse rate, and temperature-were made while the infant was resting quietly, and therefore sometimes had to be postponed or omitted. These values were recorded at 0800 and 1600 hours, and at other times as necessary. Blood pressure was determined in standard manner by ausculation, using a Doppler ultrasound flow meter for the very small infants. Liver size below the right costal margin was measured through several respiratory cycles, by the same observer, with a paper tape along an imaginary line from the right nipple to the umbilicus; the average of these measurements was recorded as degree of hepatomegaly. Vomiting was recorded; $>15 \mathrm{ml}$ was considered true vomitus volume, not just regurgitation. The time of vomiting, quality, quantity, and content were recorded.

A random urine sample was analysed for $\mathrm{Na}^{+}$and $\mathrm{K}^{+}$concentration each day. Plasma $\mathrm{Na}^{+}, \mathrm{K}^{+}, \mathrm{Cl}^{-}$, and $\mathrm{HCO}_{3}{ }^{-}$, and blood $\mathrm{pH}, \mathrm{PCO}_{2}$, plasma urea,

*A dry cereal normally mixed with milk, similar to porridge or Farex. random plasma glucose, and the plasma digoxin level were determined twice weekly. The plasma level of digoxin was determined and an electrocardiogram was performed more often in the event of vomiting or cardiac dysrhythmia if this was thought to be due to digoxin toxicity.

All the data for each patient were recorded daily on flow-sheets. Values were calculated as mean \pm SEM. For each patient, each day the morning and afternoon respiratory and pulse rates were averaged, and liver size, respiration, pulse rate, and body weight were analysed by paired $t$ tests and compared with day 1 findings. Student's $t$ was used to determine significance of differences between the two groups.

At discharge, an appointment was made for the infant to be brought to the cardiology outpatient clinic. At that time the clinical history and assessment were again recorded together with vital signs, electrocardiograms, chest roentgenograms, and bloodchemistry values. If the infant was readmitted before the clinic visit, the new admission history and assessment were used for follow-up data.

\section{Study patients}

The study lasted 15 months. It was completed in 21 (12 girls, 9 boys) infants aged $1-12$ (mean $2 \cdot 6 \pm 0 \cdot 55)$ months. Ten group A infants received a conventional potassium supplement and 11 group $B$ infants were given spironolactone in addition to digoxin and diuretics. In group A mean age was $1 \cdot 8( \pm \mathrm{SEM} 0 \cdot 49)$ months, height $53.9( \pm 1.39) \mathrm{cm}$, and weight 3.397 $( \pm 0 \cdot 1798) \mathrm{kg}$. In group B mean age was $3 \cdot 3( \pm 0 \cdot 94)$ months, height $57.94( \pm 2.638) \mathrm{cm}$, and weight $4.404( \pm 0.4067) \mathrm{kg}$. The type of congenital heart defect varied from complex to simple large ventricular septal defects but was similar in each group.

\section{Results}

On entry into the study, group mean ages and heights did not differ appreciably but mean weight was significantly greater in group B than in group A $(P<0.05)$. Mean daily weight fell for group $B$ but not for group A (Fig. 1). Paired $t$ test analysis for day-by-day comparisons of individual patient's weights showed highly significant decreases $(\mathbf{P}<\mathbf{0} \cdot 01)$ in group B $(2.24$ to $3.12 \%)$ for the first 6 study days, while all patients were still in the study. In group $A$, significant decreases $(2.59$ to $3.12 \%(P<0.05))$ occurred only on days $2,4(n=10)$, and $7(n=8)$.

Initially, mean liver enlargement was comparable in the two groups (group A $3 \cdot 85 \pm 0 \cdot 248$; group B $3 \cdot 70 \pm 0 \cdot 259 \mathrm{~cm}$ ). Comparisons of daily means with day 1 showed significant decreases in hepatomegaly in both groups, particularly in group B (Fig. 2). Both groups showed significant decreases in degree of 


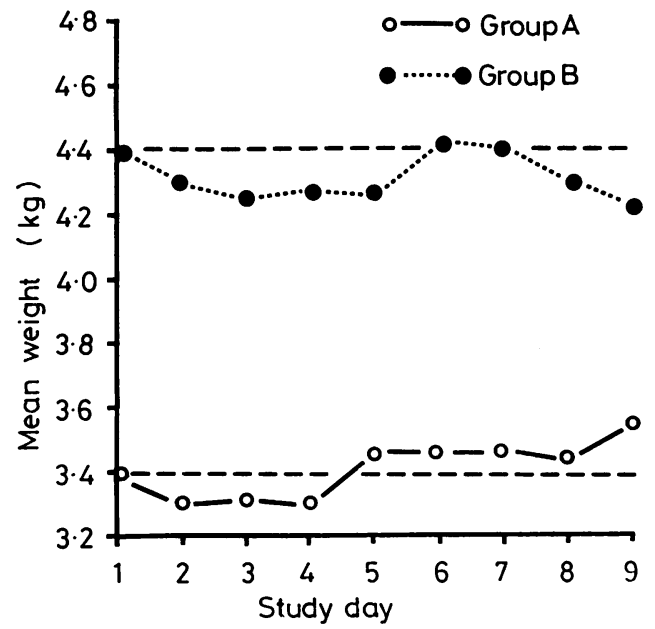

Fig. 1 Mean daily weights of patients in each group, for each study day. Group B received spironolactone.

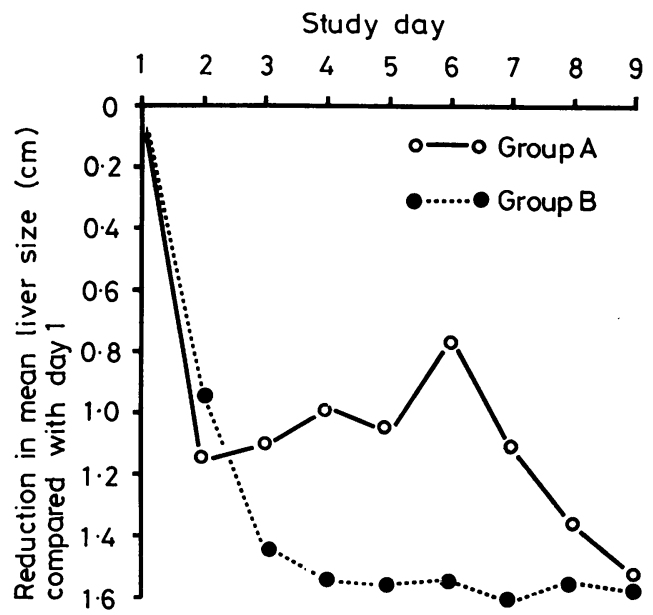

Fig. 2 Reduction in mean hepatic size compared with day 1, for each study day.

hepatomegaly by paired comparisons with each patient's first study day but the decrease was consistently greater in group B after day 2; the maximum decrease was $32.7 \%(P<0.01)$ in group $A$ and $41.8 \%(P<0.01)$ in group $B$.

Mean respiratory rate decreased significantly in both groups, rather erratically in group A (Fig. 3). Statistically significant decrease in respiratory rates began on study day 4 in group B but not until day 6 in group $A$. The pulse rate decreased significantly (by Student's $t$ test) on days 5,7 , and 8 in group B and not at all in group A (Fig. 4).

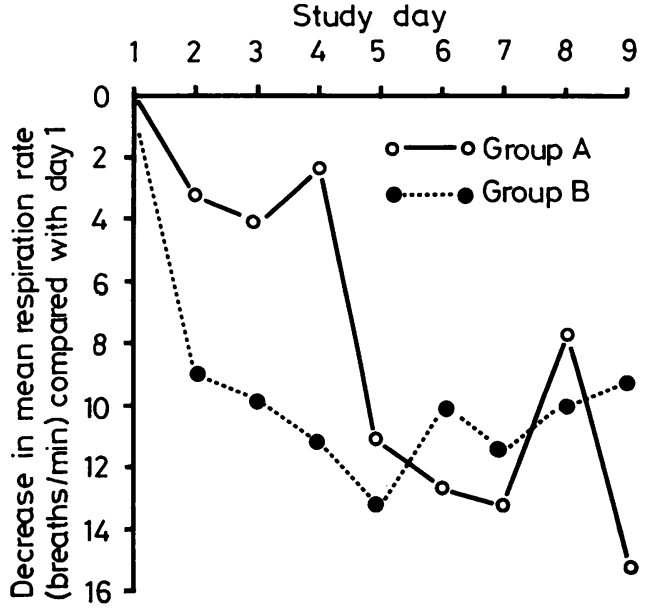

Fig. 3 Decreases in mean respiratory rate compared with day 1, for each study day.

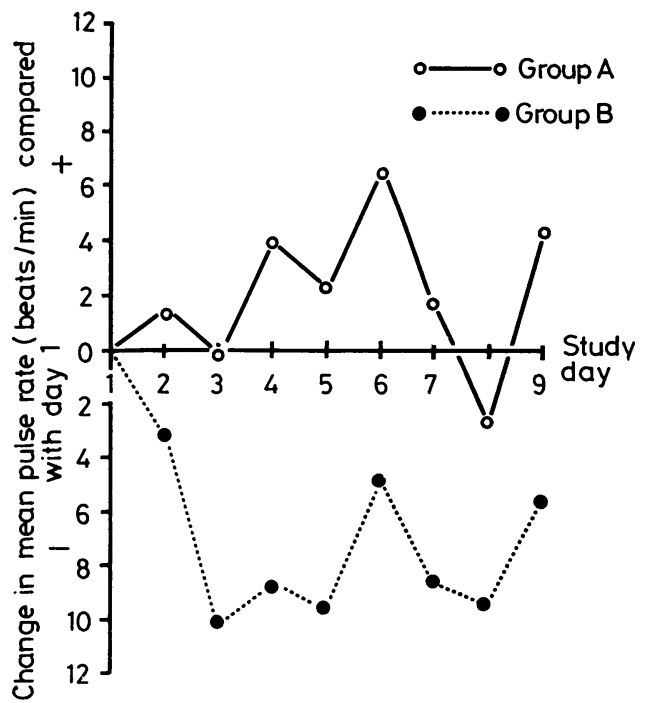

Fig. 4 Change in mean pulse rate compared with day 1 , for each study day.

Fifteen vomiting episodes were recorded for each group, within 1 hour of ingestion of medication on 5 occasions in group A and on 3 occasions in group $\underset{\mathrm{N}}{\mathrm{N}}$ B. Seven of the 10 patients in group $B$ and only 4 of the 11 patients in group A did not vomit, but there were no significant differences between groups (episodes of vomiting per day $=0.148$ in group $A$, and $0 \cdot 124$ in group B). 
Initial mean plasma $\mathrm{Na}^{+}$values of the two groups were comparable. In group $\mathrm{A}$, mean plasma $\mathrm{Na}^{+}$ values changed little. In group B however, the second and third mean values were significantly lower $(P<0.05)$ than the first, decreasing from 138.7 $( \pm 0 \cdot 78)$ to $136 \cdot 1( \pm 0 \cdot 77)$ to $134.4( \pm 1 \cdot 75)$. Similar numbers of abnormal values for plasma $\mathrm{Na}^{+}, \mathrm{K}^{+}$, $\mathrm{Cl}^{-}$, and plasma urea were observed in each group and the group means were never significantly different. No abnormal laboratory findings were clinically significant.

There were no significant inter- or intragroup differences in plasma digoxin concentrations (range 0.8 to 4.0 in group $A$, and 0.8 to $3.9 \mathrm{ng} / \mathrm{ml}$ in group B; mean $1.96 \pm 0.196$ and $1.92 \pm 0 \cdot 111$ ).

There was no significant difference for duration of time in the study; group A $10 \cdot 1 \pm 1 \cdot 62$, group B $11.0 \pm 0.83$ days. Three patients in each group left the study for surgical correction of cardiovascular defects. In group A, K-lyte was stopped for 4 infants because of lack of response of the CHF and was replaced by spironolactone, and 3 infants who were discharged to continue treatment (including K-lyte) were readmitted 6 to 24 days later, 2 with uncontrolled $\mathrm{CHF}$ and vomiting. In group $\mathrm{B}, 8$ patients were discharged to continue treatment including spironolactone; 4 were readmitted, 1 patient 4 days later with a respiratory infection, 1 patient 2 weeks later requiring dosage increases, and 2 patients (one 9 days and the other 3 months later) with CHF.

Clinical assessment and electrocardiogram indicated no adverse effect of treatment in either group.

\section{Discussion}

Spironolactone displaces aldosterone from the receptor sites responsible for $\mathrm{Na}$ reabsorption. The site of action of aldosterone and aldosteroneblocking agents is in the distal tubule; ${ }^{5}$ spironolactones do not interfere with aldosterone synthesis. By itself spironolactone generally produces only slight diuresis, requiring concomitant administration of a diuretic that inhibits $\mathrm{Na}$ reabsorption proximal to the distal tubule (for example, thiazide, frusemide, or ethacrynic acid). ${ }^{6}$ Its maximal natriuretic effect develops within a few days.

The role of aldosterone in the development and maintenance of oedema in CHF remains poorly defined, despite numerous studies. For example, rates of secretion or excretion before treatment with diuretics have been reported as increased, ${ }^{7}$ normal, ${ }^{8-10}$ and variable. ${ }^{11}$ Nicholls et al. ${ }^{12}$ demonstrated normal or raised aldosterone levels before treatment and considered that the renin-angiotensin system was the most important regulator of aldosterone secretion. Spironolactone is reported to increase renal $\mathrm{Na}$ excretion in patients who have $\mathrm{CHF}$ and normal or low rates of aldosterone excretion. Thus, a diuretic response to spironolactone is not a reliable indication of hyperaldosteronism in oedematous patients. ${ }^{13}$

Reports of the use of spironolactone in infants with CHF are few, even though this drug is fairly widely used as an adjuvant to other anti-failure medications. Baylen et al. ${ }^{14}$ documented greatly increased aldosterone levels in 6 of 8 infants in CHF secondary to congenital heart disease, and significantly decreased levels (and clinical resolution of the CHF) in 4 of the infants after adding an aldosterone antagonist. Thus it seems appropriate to consider hyperaldosteronism as an added factor in CHF, and digoxin, chlorothiazide, and spironolactone as appropriate therapy.

\section{Implications}

Changes in body weight are commonly used for comparison of volume changes in oedematous states. ${ }^{15}$ In our study, body weight decrease was greater, faster, and more consistent in the infants given spironolactone. This drug appeared to confer other benefits, compared with K-lyte. It decreased hepatomegaly more markedly and faster and, being more palatable, gave rise to a lower incidence of vomiting. It also lowered resting respiratory and pulse rates more easily. Plasma $\mathrm{K}^{+}$levels were wellcontrolled in both groups, and similar electrolyte disturbances, common in patients with $\mathrm{CHF}$ (decreased serum $\mathrm{Na}^{+}, \mathrm{Cl}^{-}, \mathrm{HCO}_{3}{ }^{-}$, and blood $\mathrm{pH}$ ), occurred in both groups.

Group B patients who have continued treatment (including spironolactone) were progressing well clinically when seen at follow-up. In view of these findings we now prescribe this $\mathrm{K}$-sparing diuretic as an adjunct to digoxin and thiazide diuretic to enhance and accelerate the capacity to decrease liver size and body weight and provide more normal and stable respiratory and pulse rates.

We thank G D Searle and Company of Canada Limited for their gift of $5 \mathrm{mg}$ Aldactone tablets and for statistical analysis and advice, and the Medical Publications Department of the Hospital for Sick Children, Toronto, for technical assistance.

\section{References}

1 Kagawa C M, Sturtevant F M, Van Arman C G. Pharmacology of a new steroid that blocks salt activity of aldosterone and desoxycorticosterone. J Pharmacol Exp Ther 1959; 126: 123-30.

2 Liddle G W. Aldosterone antagonists. AMA Arch Intern Med 1958; 102: 998-1004. 
3 Rance C P, Arbus G S, Balfe J W, Kooh S W. Persistent systemic hypertension in infants and children. Pediatr Clin North Am 1974; 21: 801-24.

4 Cohen S N, Doyle E F, Rutowski M M. Drug therapy of heart disease in pediatric patients. I. Congestive heart failure in infancy and concepts of developmental pharmacology. Am Heart J 1973; 86: 133-7.

5 Vander A J, Wilde W S, Malvin R L. Stop flow analysis of aldosterone and steroidal antagonist SC-8109 on renal tubular sodium transport kinetics. Proc Soc Exp Biol Med 1960; 103: 525-7.

- Heinemann H O. Acid-base balance and intravenous fluid therapy. In: DiPalma J R, ed. Drill's pharmacology in medicine, fourth edition. New York: McGraw-Hill, 1971: 871-91.

7 Lenzi F, Caniggia A, DiPerri T, Guideri R, Ravenni G. Aldosterone in congestive heart failure. Acta Med Scand 1959; 163: 329-39.

8 Cox J R, Davies-Jones G A B, Leonard P J. Sodium content and urinary aldosterone excretion in patients with congestive heart failure before and after treatment and comparison with normal subjects undergoing salt restriction. Clin Sci 1964; 26: 177-84.

9 Hickie J B, Lazarus L. Aldosterone and metabolism in cardiac failure. Aust Ann Med 1966; 15: 289-300.

10 Laragh $\mathbf{J}$ H. Hormones and the pathogenesis of congestive heart failure: vasopressin, aldosterone, and angiotensin. II. Further evidence for renal-adrenal interaction from studies in hypertension and in cirrhosis. Circulation 1962; 25: 1015-23.

11 Wolff H P, Koczorek K R, Buchborn E. Hyperaldosteronism in heart disease. Lancet 1957; ii: 63-6.

12 Nicholls M G, Espiner E A, Donald R A, Hughes $H$. Aldosterone and its regulation during diuresis in patients with gross congestive heart failure. Clin Sci Mol Med 1974; 47: 301-15.

13 Carruthers B M, Ledray R D, Seraglia M, McIntosh H W, Baird M M, Walsh G C. Effect of an aldosterone antagonist (spironolactone) on patients with severe congestive heart failure. Can Med Assoc $J$ 1963; 89: 633-41.

14 Baylen B, Johnson G, Tsang R, Srivastava L, Kaplan S. The role of aldosterone and aldosterone antagonists in congestive heart failure in infancy (abstract). Am $J$ Cardiol 1976; 37: 120.

15 Friedberg C K. Diseases of the heart, third edition. Philadelphia: Saunders, 1966: 408-26.

Correspondence to Dr S M Hobbins, Hospital for Sick Children, Cardiology Division, 555 University Avenue, Toronto, Ontario, Canada M5G 1X8.

Received 8 December 1980

\section{The following articles will appear in future issues of this journal:}

Fatal infection with echovirus 11

$P J$ Berry and $J$ Nagington

Klinefelter's syndrome in adolescence

$S G$ Ratcliffe, $J$ Bancroft, D Axworthy, and W McLaren

Delayed clearance of pulmonary fluid in the neonate

$S$ Rimmer and J Fawcitt

Corticosteroid-induced cataracts in idiopathic nephrotic syndrome

$J T$ Brocklebank, $R$ B Harcourt, and S R Meadow

Effect of feeding on infants' faecal flora

$A$ Simhon, $J R$ Douglas, B S Drasar, and J F Soothill

Determinants of stress for staff in a neonatal intensive care unit

$J$ Astbury and $V Y H Y u$ 